\title{
Considering the place of practice-based evidence within Evidence Based Library and Information Practice (EBLIP)
}

\author{
Denise Koufogiannakis
}

\begin{abstract}
Since its inception, the focus of evidence based library and information practice (EBLIP) has been on research evidence, although many other factors also contribute to professional decision making. This paper draws upon practice theory and examples of practice-based evidence in other professions in order to explore how practice-based evidence should be factored into the EBLIP model. Examples of how practitioners can use practice-based evidence within their decision making, and how the EBLIP model can include practice-based evidence, are also presented.
\end{abstract}

\section{Introduction}

Evidence based library and information practice (EBLIP) is an approach to information science that promotes the collection, interpretation and integration of valid, important and applicable user-reported, librarian observed, and research-derived evidence. The best available evidence, moderated by user needs and preferences, is applied to improve the quality of professional judgements

(Booth, 2000).

The movement began in the late-1990s, with early mention in Hypothesis, a publication of the Medical Library Association (Eldredge, 1997). Early proponents within health sciences librarianship, who had been assisting physicians and nurses with evidence based health care, wanted to apply the same principles of evidence based practice to their own profession.

Since that time EBLIP has made strides towards preparing practitioners in the field to use and incorporate research evidence into their practice. Several critical appraisal guidelines have been created (Booth and Brice, 2003; Glynn, 2006; Koufogiannakis, Booth and Brettle, 2006), there have been numerous workshops

\section{Author}

Denise Koufogiannakis is a Collections and Acquisitions Coordinator at the University of Alberta Libraries in Edmonton, AB, Canada.

Email: denise.koufogiannakis@ualberta.ca 
to teach librarians about research skills, and the journal Evidence Based Library and Information Practice is now in its sixth year of publishing evidence summaries that critically appraise recent LIS research studies.

The EBLIP movement has focused on incorporating research into decision making. This is a noble and worthwhile goal, and practitioners have responded with enthusiasm in wanting to learn these skills and bring research into their practice. This is witnessed via the growth of the international Evidence Based Library and Information Practice conferences since the first took place in 2001, as well as in the growth of papers being published on the topic.

EBLIP is largely driven by practitioners who want to improve their practice. This paper contends, however, that the focus of EBLIP over the past 15 years has neglected to incorporate the role of user-centred evidence parts of what the movement in fact defines itself to include, namely the user-reported and librarian observed forms of evidence that are included in the above definition. The EBLIP movement has now progressed to the point where it is clear that the very use of research evidence in practice is often problematic, and complicated. It is not as straightforward as taking the research someone else has done and simply implementing it. Booth provides a synthesis of the evidence on these barriers to implementation of evidence based practice in LIS (Booth, 2011). Such barriers show that research is not used in isolation, but rather amidst numerous social and environmental factors, and must be placed in the context of a local situation.

This paper will explore some of the non-research types of evidence that are important to librarian practice, and make the argument for why these forms of evidence need to be equally and explicitly considered alongside research-derived evidence if a model of evidence based practice is truly going to be useful and meaningful for practitioners.

\section{Evidence Based Practice in LIS}

Based in the vein of evidence based medicine, a model began to emerge for evidence based practice in library and information studies (now referred to generally as evidence based library and information practice) in the late 1990s. The model for evidence based practice follows 5 steps (Centre for Evidence Based Medicine, 2009), often referred to as the $5 \mathrm{~A}$ 's, which are illustrated in the following diagram (Figure 1):

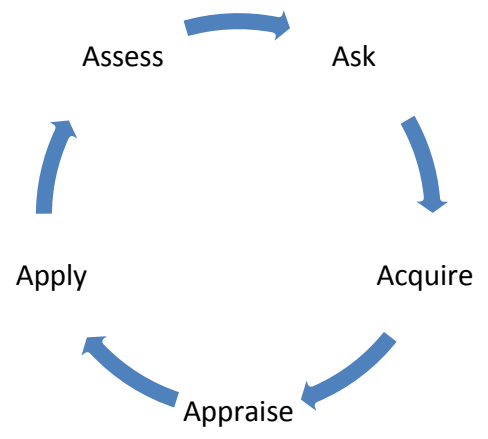

Figure 1: Current model for evidence based practice. 
This model provides a structure to approach decision making. It begins with an issue or problem that arises in the workplace - an area in which librarians are looking to improve service. The problem may start out somewhat vague, and must be formulated into an answerable, well-built question (Ask). A well-built question helps to determine some of the key terms that will be used in a search strategy. Depending upon the subject area or domain that the question falls into, databases within and beyond the library literature are searched to find research evidence (Acquire). Once relevant research is found on the topic, the evidence is critically appraised to determine if it is valid, reliable, and applicable to the librarian's situation (Appraise). This knowledge is then applied to the librarian's practice (Apply). The final step is to evaluate this process and determine what impact was made, where gaps remain, and where improvement is needed for next time (Assess). EBLIP is meant to be a continual cycle of improvement for the way librarians work and make decisions. An overview of this approach is outlined in the book Evidence-Based Practice for Information Professionals, edited by Andrew Booth and Anne Brice.

To date, the focus of EBLIP has been on research-based evidence. For example, an examination of the continuing education sessions at the bi-annual EBLIP conference reveals a focus on critical appraisal, as well as specific research methods such as cohort studies, randomized controlled trials, and meta-analysis. In addition, most general workshops or continuing education sessions that give overviews of EBLIP focus on finding and critically appraising research evidence. With the most recent conference, held in Salford, UK, in June 2011, there has been a small shift with one of the four workshops dedicated to reflective practice, which was also one of the themes of the conference.

Even within the focus on research evidence, there is a further concentration regarding which type of research is best. This is most evident in the hierarchy of evidence pyramid (Eldredge, 2000, 2002, 2006), which does not place these levels of research evidence within any kind of situational context. To a librarian viewing such a diagram, it is clear that EBLIP favours certain types of scientific research more than others (i.e.: meta-analysis, randomized controlled trials). At the bottom of the hierarchy are 'lower' forms of evidence such as case studies, descriptive studies, opinion, and surveys, along with qualitative research. Evidence that is gathered at a local level, such as usage statistics, or patron feedback is not even considered within the pyramid.

The situating of qualitative evidence at the bottom of the evidence pyramid has been a common criticism of evidence based practice, with Given noting in 2006 that it has led to

disenfranchise qualitative research from the EBL process, and to discredit the results of qualitative work without further (quantitative) investigation of the conclusions that those studies draw.

(Given, 2006, 381)

Anything other than positivistic, scientific evidence has been demoted, and this creates a wide crack in the goal of enabling LIS professionals to practice in an evidence based manner, since the notion of a hierarchy and what is represented 
therein, is so far removed from the reality of practitioners' experiences and what is valuable evidence to them. While some have explicitly questioned this hierarchy and call for its end (Crumley and Koufogiannakis, 2002; Banks, 2008; Booth, 2010; Koufogiannakis, 2010), it seems to have become a recognized part of EBLIP.

Evidence based practice requires research; research is an important part of being evidence based and making good decisions. However, there are other forms of evidence that are also valid and worthy, which practitioners encounter every day, such as librarian observation, the gathering of patron-centred feedback, and professional knowledge. These are not less worthy forms of evidence - they are just different forms of evidence. Depending upon the situation, the context, and the local need, these forms of practice-based evidence are clearly vital and important to evidence based decision making. Practice-based evidence has a focus on the practice environment, rather than the research environment. It is the gathering of data and other forms of local evidence that are found in practice situations, linked together with librarian expertise. In many cases, this is much more important than research evidence, because local information addresses the needs or concerns of the very people we are trying to serve within our specific communities. It tells us exactly what people from our community think, or shows us what they do and how they use our services.

\section{The Problem}

Rycroff-Malone et al (2004) state that that in order for evidence based practice (in nursing) to create a broader evidence base, "the external, scientific and the internal, intuitive" need to be brought together. The external, scientific is what evidence based practice has been focused on, in the form of scientific research, but Rycroff-Malone et al note that other elements such as clinical experience, patient experience, and information from the local context also need to be considered.

The focus of EBLIP over the past 15 years has been on scientific research. It has neglected to incorporate the role of user-reported and librarian observed forms of evidence. There has been a lack of consideration about how research evidence might be implemented alongside other forms of evidence, and within particular contexts. What about other things librarians use in decision making, like usage stats, user feedback, our own knowledge of a particular situation? Is there a place for these types of sources? And is formal, published research always the best evidence?

The aim of this paper is to investigate those questions, through the lens of practice, by asking:

- In the practice of librarianship, what types of evidence influence our decision making?

- How do we account for non-research evidence in EBLIP? Where does it fit in an evidence based model? 
This paper explores these questions via a reading of the practice theory literature, as well as the literature on practice based evidence, and applying those concepts to library and information practice.

\section{A Practice Based Perspective}

Librarianship is a practice, and therefore can be viewed through the lens of practice theory. Practice theory considers how groups of people have shared practical understandings which are based on actions and must be considered within a specific context. This includes elements of tacit knowledge, practical judgement, and societal agreement. Practice theory exposes additional factors beyond research and scientific knowledge that should be considered to fully understand a librarian's way of practicing and arriving at decisions related to professional practice. It looks to practice rather than research to guide what we know about how we function as a practice.

Practice theory arose in the writings of social theorists, Bourdieu (1972), and Giddens $(1979,1984)$. Wittgenstein and Heidegger are also noted philosophers of influence in this movement. However, it was Schatzki's (1996) book, Social Practices, that was the first to wholly focus on the practice concept. In that seminal work, Schatzki outlines the theory of practices and the necessity of action within practice.

It may be useful to begin with defining what a practice is. Reckwitz notes that A 'practice' (praktik) is a routinized type of behaviour which consists of several elements, interconnected to one another: forms of bodily activities, forms of mental activities, 'things' and their use, a background knowledge in the form of understanding, know-how, states of emotion and motivational knowledge.

(Reckwitz, 2002, 249).

Schatzki sees a practice as

a set of considerations that governs how people act. It rules actions not by specifying particular actions to perform, but by offering matters to be taken account of when acting and choosing.

(Schatzki,1996, 96).

Schatzki notes that there is not a single approach to practice theory, but practice theorists concern themselves with "arrays of activity" generally associated with humans, and with "embodied capacities such as know-how, skills, tacit understanding, and dispositions." (Schatzki, 2001, 7). Gherardi situates practices as "patterns of socially sustained action". She states

A practice is not recognizable outside its intersubjectively created meaning, and what makes possible the competent reproduction of a practice over and over again and its refinement while being practice (or its abandonment) is the constant negotiation of what is thought to be a correct or incorrect way of practising within the community of its practitioners.

(Gherardi, 2009, 536). 
Reckwitz (2002) compares and summarizes the writings of various practice theorists to expose the main concepts shared by the majority of them. He paints a clearer picture of what the essential elements of this type of theory are. He notes that practice theory is a type of cultural theory which highlights "the significance of shared or collective symbolic structures of knowledge in order to grasp both action and social order" (Reckwitz, 2002, 46). Individuals carry elements of a particular practice with them, but those elements are not unique qualities of the individual. Physical and mental activities are routinized and a shared understanding exists amongst the group, and even observers of the group. "A practice is thus a routinized way in which bodies are moved, objects are handled, subjects are treated, things are described and the world is understood." (Reckwitz, 2002, 250).

In librarianship, we have particular behaviours that are comprised of mental and bodily actions. An example is reference services where we need to use such devices as a computer, the catalogue, etc; but within these physical actions, we also have mental actions that go hand-in-hand with the physical. For example, knowledge of how to conduct a reference interview, and making a determination of the best way to answer the patron's question. As librarians, we govern ourselves according to certain agreed upon and identifiable rules or behaviours, which we have learned both from our training and experience. This does not mean that every individual does everything exactly the same, but that we operate a body of practice within a shared general framework, which our practicing body can change over time, and which practitioners know and understand. Within our shared general framework, for example, would be such concepts as access to information, organization and retrieval of information, as well as delivery of reference and instruction services, and principles of collection building, to name a few.

\subsection{Knowing in Practice}

A key element of practice theory that is directly applicable to evidence based practice is the concept of knowing in practice. In practice, knowing has two elements that cannot be separated - these are: "knowing how" and "knowing that", phrases first coined by Ryle in 1949. Knowing that relates to the mind, and how to do a particular thing, so that it is explainable. Knowing how relates to doing the thing, or action, even if one does not know how to explain how they have done it. Knowing how relates to tacit knowledge, those things that we know but cannot easily explain, a knowledge which is formed through the action itself. I.e.: knowing how to ride a bike. Polanyi was the first to delve into tacit knowledge, explaining it as "we can know more than we can tell" (Polanyi, 1966, 4). Particularly relevant to evidence based practice, Polanyi notes that the very act of problem solving, asking questions, and finding solutions requires tacit knowledge for the "act of knowing exercises a personal judgment in relating evidence to an external reality, an aspect of which he [the researcher or problem solver] is seeking to apprehend." (Polanyi, 1966, 25).

Schön, building upon the work of Polanyi, writes in his 1983 influential work, The Reflective Practitioner: How Professionals Think in Action, that "our knowing is in our action" (Schön, 1983, 49). For Schön the work life of a professional 
depends on this tacit knowing in action. Professionals make judgements of quality and display particular skills that the practitioner him or her-self may not be able to adequately explain. Schön says "Even when [the practitioner] makes conscious use of research-based theories and techniques, he is dependent on tacit recognitions, judgements, and skilful performances." (Schön, 1983, 50). So, the two aspects, research and professional knowledge, must go hand in hand.

Orlikowski (2002) reinforces that knowing is an active process that happens within practice, and that tacit knowledge is inseparable from action since the knowing found in tacit knowledge happens via action of the practitioner. Knowing in practice is a key component of how we practice our profession. It cannot simply be ignored. It is a critical piece of our activity in practice, contributing to the completeness in our practice. We cannot practice without this type of knowing and ability, and hence, in terms of evidence based practice, this know-how that practitioners' possess is an important element of evidence that should be considered alongside the more explicit research knowledge.

\section{Why including other forms of evidence is important}

Research cannot be removed from practice. The two must co-exist. A model of EBLIP should look at the whole of evidence, including that driven by practice as well as research. We need to take a different look at how evidence may be used in practice, and tie research and practice together rather than separating them. A first step is to recognize that what practitioners do is of utmost importance. Obviously, without the practitioner, there is no practice, and practitioners are the ones who are going to know what is happening within their context. Practitioners bring evidence to the table through the very action of their practice. Local context of the practitioner is the key, and research cannot just be simply handed over for a practitioner to implement. The practitioner can use such research to inform themselves, but other components are also important. The concepts found in practice theory, focusing on the practitioner and their knowing in practice - both local evidence and professional knowledge, help to provide a more complete picture of decision making within our profession.

Looking beyond theory, several other professions are beginning to embrace a practice-based evidence approach in addition to an evidence based practice one. In Medicine and Nursing, Gabbay and Le May have done ethnographic research to reveal how clinicians acquire and use their knowledge. Their 2011 book, details the results of this research and their illumination of the clinician's use of "mindlines" which refers to

collectively reinforced and often tacit guidelines that are informed by clinicians' training, by their own and each others' experiences, by their interactions with their role sets, by their reading, by the way they have learnt to handle the conflicting demands, by their understanding of local circumstances and systems, and by a host of other sources.

(Gabbay and Le May, 2011, 44)

In Sociology, Fox (2003) suggests a practice-based research model, instead of the current academic model where research is constructed in opposition to practice. 
He looks to re-evaluate the hierarchy of knowledge which situates research evidence in a position superior to other forms of knowing. He argues that evidence-based practice should be supplemented by practice-based evidence and a model of practice-based research (PBR), wherein "research and practice are intertwined rather than opposite poles." (Fox, 2003, 86).

Rolfe, Jasper and Freshewater, in their 2011 book, emphasize the need for reflective practice over evidence based (research-based) practice. They note that "the reflective practice paradigm promotes the view that practitioners are also researchers in their own practice" (Rolfe, Jasper and Freshewater, 2011, 16) and go on to argue that this type of reflective knowledge is just as important as empirical knowledge. Similarly, Usher and Bryant (1989) make a strong case for the role of local context in judgement and reasoning. They note that:

every context is likely to have its own distinctive features which will both provide possibilities and impose constraints on what can be done. The practitioner therefore needs to have a situational or contextual knowledge which encompasses an understanding of these possibilities and constraints, and an awareness of their implications for action. Furthermore, contexts are also likely to be continually changing, and so the practitioner's situational knowledge must be correspondingly flexible and dynamic.

(Usher and Bryant, 1989, 75).

It is this context specific information that is most important, for ultimately, as Usher and Bryant note, it is judgement and reasoning that must stand the test of practice and be responsible to the situation at hand.

Schön encourages reflection on our professional actions and tacit knowing. He notes that as we work through situations in practice, we question and ask ourselves how we made a judgment and how we are approaching the problem. Being reflective on such situations allows us to also become more aware of aspects embedded into our actions, which themselves can be reflected upon and restructured. Schön notes,

It is this entire process of reflection-in-action which is central to the 'art' by which practitioners sometimes deal well with situations of uncertainty, instability, uniqueness, and value conflict.

(Schön, 1983, 50)

Bringing together the art and science of our profession, is certainly something we need to embrace in evidence based practice. Otherwise, the research evidence becomes meaningless to practitioners who may see it as so removed from their daily work and needs. As I have recently noted:

We need to embrace both the science and the art of evidence based practiceotherwise, we will overlook important elements of the whole situation that practitioners work within. Doing so is not neat and tidy, but does that really matter? LIS is a social science, and the "social" implies "messy" because people and real-life situations are not easily controlled. The art of our craft allows us to embrace the messy situation, find ways to be creative, put our professional judgements to use and find the best solutions to meet the needs of individual users 
by applying the best of what we find in the research literature together with the best of what we know is likely to help this person.

(Koufogiannakis, 2011, 2)

Schön reminds us that in most professions,

large zones of practice present problematic situations which do not lend themselves to applied science. What is more, there is a disturbing tendency for research and practice to follow divergent paths. Practitioners and researchers tend increasingly to live in different worlds, pursue different enterprises, and have little to say to one another.

(Schön, 1983, 308)

This sentiment has been noted previously in the LIS literature (for examples, see Haddow and Klobas, 2004), and continues to remain a common complaint of practitioners. Schön goes on to propose that if we reject the traditional idea of professional knowledge that resides with the researcher and is passed down to practitioners, we can reframe the relationship between research and practice. Schön argues that research is an activity of practitioners and that practitioners "may become reflective researchers in situations of uncertainty, instability, uniqueness, and conflict" (Schön, 1983, 308).

Following on this, Fox notes, if we reorient our thinking away from privileging those scientific, positivistic, forms of research that we see exemplified in the hierarchy of evidence, then

research and practice are no longer to be seen as in opposition. Rather, they are both aspects of a continuum of human activity and are constituted in relation, one to the other. Research cannot be irrelevant because it is by necessity and definition engaged with practice.

(Fox, 2003, 97)

\section{Types of evidence found in practice that have not been emphasized in the EBP Model}

Looking at the EBLIP model through the lens of practice theory leads to an understanding of other forms of evidence that are usually excluded from that model. The model as it currently stands is one which Schön would have noted as a "technical-rationality model" (Schön, 1983, 21-69) that excludes elements of knowing that should be considered and integrated into our practice. Applying practice-based principles to EBLIP, I determined that in addition to research there are two other broad areas that contribute evidence for decision making. Together with research knowledge, we must also look to local evidence, and professional knowledge. These three things together constitute a more realistic view of evidence that is used in LIS practice.

\subsection{Local evidence}

While research evidence is of high importance to our profession and knowledge, LIS practitioners need to first of all consider local evidence. Local evidence is found in our working environment and is specific to the context in which we carry 
out our work. It includes such things as our experience with patrons in particular contexts, and what we observe to work in our interactions, assessment of programs, feedback from our users, project evaluations, and accumulated experiences over the course of careers. These things are not easily shared and often do not find a place in publications because they are too local. But data that comes from a local context is in fact often the most important evidence source that a LIS professional can consult because it gives us information that is directly applicable to, and about our users. For example, usage stats on e-journals, feedback and comments about our services, usability testing on our website, titles from our interlibrary loan requests; these are just a few examples of local evidence that is invaluable to our decision making. This local data doesn't often mean much to others outside of our organization, but it is of utmost importance to our situated knowledge. The trick is to figure out what local information to systematically collect, and how to use it.

Types of local evidence:

- Patron feedback - as you receive feedback it alerts you to the fact that something may need to change, or lends support for what you are doing. This usually comes in an informal way, via email or face to face discussions at your place of work. Over time, you can note trends and needs, and use this evidence to further explore what may need to change.

- Librarian observation - every day we observe things as we practice. This may be as simple as noting something like the fact that all the computer terminals are busy and there is a queue for most of the day, every day. Such observations tell us things about our environment and whether our users are able to effectively use our programs and spaces.

- Discussions/interactions with colleagues - hopefully we do not work in isolation, but have colleagues with whom we can share and discuss experiences, as well as brainstorm solutions and innovations. If colleagues are mostly observing or hearing similar types of things, this lends further credibility to what we may have seen or heard ourselves regarding a particular issue. Reports from colleagues may also contradict our own notions, and give us pause for thought before charging ahead with something.

- Assessment and evaluation of programs - assessment and evaluation can be done on many different levels. Some institutions have librarians assigned to this role, and they may be responsible for data gathering on major initiatives happening within the library, as well as reporting of library statistics. However, any librarian can and should evaluate the programs or services they are offering, in order to verify that outcomes are being met and program deliverables are successful.

- Usage data - we already have a lot of data at our disposal that can help with decision making. Usage data gives us a better idea of the popularity and need of certain databases, journals, and books. Usage data may comprise the usage stats given to us by online vendors or publishers, our in-house circulation numbers for print items, and also other data we may be able to collect such as numbers of holds on items in our catalogue, or numbers of requests we 
receive either via ILL or a request for purchase, of items we do not carry. Likewise, we can usually obtain usage data on particular in-house services we provide or website traffic patterns. These are only a few examples, and such data cannot be looked at in isolation, but it is a valuable tool when used in context, in order to understand more about the use patterns of those we serve.

- Organizational realities - organizational realities often trump any other form of evidence we have because things such as funding and political directions that are set by the institution, are ultimately going to have to be met. Hence, we need to make decisions and look at possibilities within the light of the evidence we have about our organizational climate and its directions. If, for example, you are faced with budget cuts and have to cancel journals, that is a reality and you will need to try to make the best decisions within the new limitations on your budget. Working within our organizational realities is important and although one institution may be able to achieve something and show in the literature that it was successful, each library's circumstances may be different, and so local realities are a key element of evidence to pay attention to. This evidence comes in the form of strategic plans, budgets, discussions with administrators, and keeping abreast of emerging areas within your place of work. This is also an area where we may use previously collected data to make a case for resources and set our own priorities, for example, within a climate of fiscal restraint.

\subsection{Professional knowledge}

Librarians hold a great deal of evidence in our professional knowledge that is progressively built over the course of a career. Much of this is tacit, but worthwhile trying to draw out when possible and be made explicit so that knowledge can be shared. Evidence is shown to us every single day - as we practice our profession, we learn what works and what doesn't in certain situations in our own environments. We have practical, real-life experiences to draw upon that are grounded in different contexts. As professionals we have foundations that form the basis of our knowledge, in a field where we have already learned from our education, training, and on-the-job experience. We build up skills and know-how that are not necessarily written down, but which provide us with a great deal of specialized knowledge. As we learn how to most effectively provide good service, or build quality collections for our users, or build relationships within our community, all these things provide us with evidence of how to be a better professional. That does not mean that we can just rely on these experiences, however, but rather that through reflection and critical thinking we will see where things may be improved and begin to investigate ways to make them better. Without that initial evidence coming from our experience, we would not even know how or when to question or critique such things. Hence, the initial evidence of "what do I know" becomes an area that is crucial to future research that will be of value to practice improvement. 
Types of professional knowledge:

- Formal and informal learning - librarians who have an MLIS degree, all have a basic grounding in the theory of our profession. This contributes to our common set of values, scope, and history of our profession. Clearly, we don't learn everything in library school, but this education gives us a basis for our future practice. Throughout our careers, we need to also actively engage in ongoing education, via such venues as conference participation, workshops, online seminars, reading of the literature, and conversing with other practitioners, to name a few examples. If we do not continue to actively learn, we will no longer be able to contribute to our community of practice.

- On the job training - as we begin our careers, most librarians rely on the training and mentoring they receive from more seasoned professionals. These librarians are passing on their knowledge and skills to us so that we may also increase our professional capacity and skill in order to become better at our practice. Finding people you trust and admire, and who will give you good advice, are essential in the early years of a career. Likewise, more seasoned professionals need to continually learn new skills in order to keep up with the latest technologies being used, and thus meet the needs of users. Actively maintaining both mental and physical skills is crucial.

- Tacit knowledge - As previously noted, tacit knowledge are those things that we know but may not be able to explain. Within librarianship, I think of things like knowing how to select the right books to purchase, or how to conduct a good reference interview so that you truly help the person asking the question, or how to effectively communicate and build a rapport with faculty members. Often we can explain to others some of the strategies we use to do these things, but how to be successful in the overall process is more difficult to convey. These tacit skills are usually learned over time by doing, and are the result of our experiences.

- Reflective knowledge - reflecting on decisions we make contributes to our professional knowledge substantially. It allows us to pause and consider what went right, what went wrong, and what might be done differently next time. This process moves some of what we learn in a tacit manner into a more explicit, systematic approach, where learning and thinking and making change are all contributing to our professional knowledge. Each person needs to determine what form of reflection is best for them, and find an approach to fitting it into the day. Through reflection we become more engaged practitioners.

These are all examples of information from the local context, or from professional knowledge built up over time. They are all forms of evidence that come much more naturally to most LIS practitioners than research evidence. How can practitioners relate to EBLIP if these forms of evidence are being ignored? The EBLIP movement needs to start from the position of these practice-based forms of evidence, and then work towards how research evidence fits within a practitioner's context, because practitioners are the ones in a position to change practice. We are individual practitioners but we operate within a field of practice 
that holds established norms and guides us via ongoing discussion and acceptance. This is why we continue to change and evolve as society changes and evolves. Research needs to speak to this practice-based environment by being meaningful and timely.

\section{Moving the EBLIP Model Forward}

Based on my reading of practice theory, and papers in other professions that discuss practice-based forms of evidence, I think we need to carefully consider where research fits with these other variables, and how all three can best work together. All three components are important, so we should not automatically privilege one over the other or make general assumptions about what is best. I propose that proponents of EBLIP also embrace the local evidence and the professional knowledge which go hand in hand with research evidence (see Figure 2). Each librarian needs to make those judgements within their own context and circumstances. If we exclude local evidence and professional knowledge from the evidence based practice framework, our model becomes largely insignificant to those very practitioners we are hoping to reach. Research cannot be considered blindly or out of context. Providing space for these other types of evidence to be equally considered alongside research evidence, makes our model more robust and practitioner-friendly.

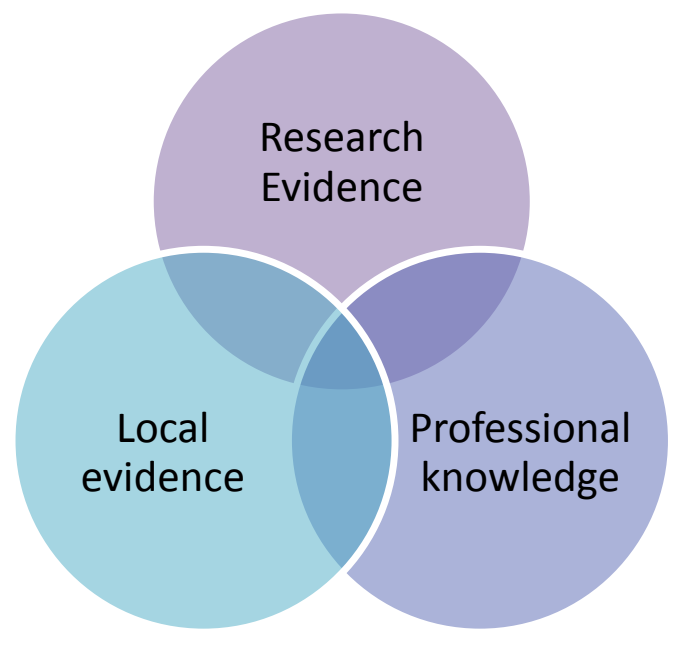

Figure 2: Bringing the evidence sources together.

The EBLIP model must continue to grow and change so that the overall approach addresses other aspects of evidence. Rather than privileging as in a hierarchy, these elements should be flattened. All forms of evidence need to be respected and the LIS professional, with their underlying knowledge is at the centre of the decision making process. Progress in our practice begins with us as professionals, not with a set chart to dictate worth of experiences or value of specific evidence. These things need to be weighed within the context in which they are found, and only the practitioners dealing with that decision can appropriately assign value and importance within that context.

There must be an emphasis on applicability, because decision making is ultimately a local endeavour. For example, EBLIP workshops should still teach such skills as how to critically appraise research, but these things should always 
be framed within the context of the importance of practice-based information, and stressing the importance of the local context. For example, letting participants know that they are not wrong to recognize political or financial influences as being more important than the research literature. These elements are facts of life and boundaries we have to live within. We cannot ignore such things. Within such boundaries we need to weigh appropriate evidence and made contextual decisions.

\subsection{Key questions for practitioners}

In practical terms, what I've just described can translate into the following questions that a LIS practitioner should ask themselves when wanting to practice in a conscious, evidence based manner (see Figure 3). First, one asks oneself, 'what do I already know?' about the question or problem at hand. This draws on both professional experience, and our knowledge of the specific situation at hand, which may have built up over a period of time. Asking yourself what you already know allows for reflection on the situation and the factors that may influence future action. Next, you ask yourself is there local evidence available. This draws upon any data, user comments, etc that you may already have collected that are important within your context and that relate to the specific problem. From there, you can look to the literature and see if there is any research that would be relevant to the problem/decision you need to make. This is where the current EBLIP model comes in, and the skills of critical appraisal of existing published work is required. Sometimes, there may not be any research on the topic, but there may be descriptions of similar situations at comparable institutions that can help you.

At this point, it is good to review all the existing evidence and ask yourself 'what other information do I need to gather?'. Doing so allows you to identify gaps in your knowledge or where you need further information to make a confident decision. At that point you can determine if you need to gather more data, speak to certain groups of people, or even set up a research project of your own. At about the same time you are considering all the evidence you have and how it applies to your situation or problem at hand. This is a crucial professional knowledge skill that puts the evidence in context. Depending upon the urgency of the situation, or deadlines you have been given, you then proceed to make your decision. This step is going to happen, based on the best evidence you have available. At a different point in time, that evidence can change, but in that moment, you make the decision. Finally, after implementation, you reflect on this process and ask yourself questions such as 'What worked? What didn't? What did I learn?'. Taking the time to assess the situation and learn from it is a key part of enhancing professional knowledge. You may also wish to set out goals for more formal evaluation if the case was one where you are beginning a new program or service, for example. 


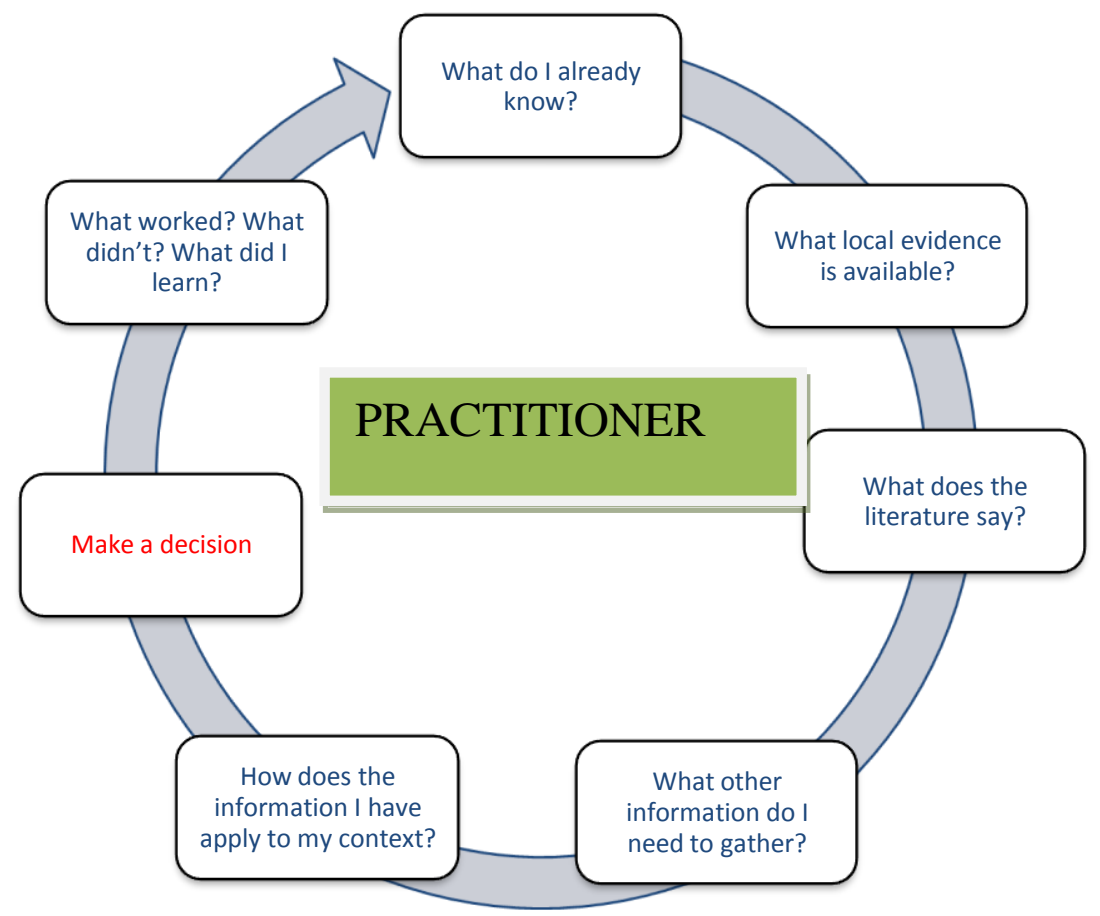

Figure 3: Key questions a practitioner should ask themselves when making professional decisions in an evidence based manner.

This process puts the practitioner back at the centre and in control of their decision making, a piece of which is research evidence, but which also considers other forms of evidence that may be more directly relevant to the practitioner. It enables us to practice in an informed and evidence based way, bringing together the art and science of our profession.

\section{Conclusion}

Librarians make practice based professional decisions every day. They will continue to do so regardless of an evidence based model. Expanding the model so that it is less abstract and more in keeping with the types of evidence practitioners use regularly, will make the model more meaningful and more encouraging for the inclusion of research to be brought into the mix. It is time to broaden our idea of evidence.

In this article I have drawn upon practice theory to explore the non-research side of decision making and evidence. I have given examples of practice-based evidence and explained why these things are important to evidence based practice in LIS. My goal is not to reduce the place of research-based evidence, but to situate it within the wider practice of librarianship, and draw attention to the other forms of evidence that are also important and will contribute to our professional decision making.

Putting together the published research evidence with local evidence and professional knowledge is not an easy task. It resides in each individual professional who wishes to do their best work while including research evidence to support that work. A person of this nature will be both reflective of their skills as a practitioner, and continue to consciously think about what they do in practice. 
They will look to the literature for support, gaining further insights and building upon their own knowledge. This thoughtful approach to our work and the honing of our craft will allow for growth, revitalization and action within our profession.

\section{References}

Banks, M. (2008) Friendly skepticism about evidence based library and information practice, Evidence Based Library and Information Practice, 3(3): 8690.

Booth, A. (2000, July 2-5) Librarian heal thyself: Evidence based librarianship, useful, practical, desirable? Proceedings from the 8th International Congress on Medical Librarianship. London.

Booth, A. (2010) On hierarchies, malarkeys and anarchies of evidence, Health Information and Libraries Journal, 27: 84-88.

Booth, A. (2011) Barriers and facilitators to evidence-based library and information practice: An international perspective, Perspectives in International Librarianship. Doi: 10.5339/pil.2011.1

Booth, A., and Brice, A (2003) Clear-cut? Facilitating health librarians to use information research in practice, Health Libraries Review, 20 (1): 45-52.

Booth, A., and Brice, A., Eds. (2004) Evidence-based practice for information professionals: a handbook. London: Facet Publishing.

Boudrieu, P. (1972) Esquisee d'une theorie de la pratique, precede de trois etudes d'ethnologie kabyle. Geneva: Librairie Droz.

Centre for Evidence Based Medicine. (2009) What is EBM? URL:

http://www.cebm.net/index.aspx?o=1914 [accessed 22.8.11].

Crumley, E., and Koufogiannakis, D. (2002) Developing evidence-based

librarianship: Practical steps for implementation, Health Information and

Libraries Journal, 19: 61-70.

Eldredge, J. D. (2000) Evidence based librarianship: An overview, Bulletin of the Medical Library Association, 88(4): 289-302.

Eldredge, J.D. (2002) Evidence-based librarianship levels of evidence, Hypothesis, 16(3): 10-13.

Eldredge, J. D. (2006) Evidence-based librarianship: The EBL process, Library Hi Tech, 24(3): 341-354.

Fox, N.J. (2003) Practice-based evidence: Towards collaborative and transgressive research, Sociology, 37(1): 81-102.

Gabbay, J., and Le May, A. (2011) Practice-based Evidence for Healthcare:

Clinical Mindlines. New York: Routledge.

Gherardi, S. (2009) Practice? It's a matter of taste! Management Learning, 40(5): 535-550. 
Giddens, A. (1979) Central problems in social theory. Action, structure, and contradiction in social analysis. London: Macmillan.

Giddens, A. (1984) The construction of society. Outline of the theory of structuration. Cambridge: Polity Press.

Given, L. (2006) Qualitative research in evidence-based practice: A valuable partnership, Library Hi Tech, 24(3): 376-386.

Glynn, L. (2006) A critical appraisal tool for library and information research, Library Hi Tech, 24(3): 387-399.

Haddow, G., and Klobas, J.E. (2004) Communication of research to practice in library and information science: Closing the gap, Library \& Information Science Research, 26(1): 29-43.

Koufogiannakis, D. (2010) The appropriateness of hierarchies, Evidence Based Library and Information Practice, 5(3): 1-3.

Koufogiannakis, D., Booth, A., and Brettle, A. (2006) ReLIANT: Reader's guide to literature on interventions addressing the need for education and training, Library \& Information Research, 30(94): 44-51.

Orlikowski, W. (2002) Knowing in Practice: Enacting a Collective Capability in Distributed Organizing, Organization Science, 13(3): 249-273.

Polanyi, M. (1966) The tacit dimension. Garden City, NY: Doubleday \& Company, Inc.

Reckwitz, A. (2002) Toward a theory of social practices: A development in culturalist theorizing, European Journal of Social Theory, 5(2): 243-263.

Rycroft-Malone, J. et al., (2004) What counts as evidence in evidence-based practice? Journal of Advanced Nursing, 47(1): 81-90.

Ryle, G. (1945) Knowing how and knowing that: The Presidential address, Proceedings of the Aristotelian Society, 46: 1-16.

Schatzki, T. (1996) Social practices: A Wittgensteinian approach to human activity and the social. Cambridge: Cambridge University Press.

Schatzki, T., Knorr-Cetina, K. \& Savigny, E. (2001) The practice turn in contemporary theory. London: Routledge.

Schön, D. (1983) The reflective practitioner: how professionals think in action. U.S.A: Basic Books.

Usher, R., and Bryant, I. (1989) Adult Education as Theory, Practice and Research: The Captive Triangle. London: Routledge.

\section{Acknowledgement}

This paper is based on a presentation given at the $6^{\text {th }}$ International Evidence Based Library and Information Practice Conference, held in Salford, UK, June 27-30, 2011. 


\section{Open access and copyright}

Library and Information Research is an open access journal. A freely available copy of this paper may be downloaded from the journal's website:

http://www.cilipjournals.org.uk/lir

Copyright and associated moral rights in works published in Library and Information Research are retained by the author(s) but this paper may be used freely, with proper attribution, in educational and other non-commercial settings. 